\title{
Emotion regulation difficulties, perceived parenting and personality as predictors of health-risk behaviours among adolescents
}

\author{
Parwinder Singh ${ }^{1}$ (D) \\ Accepted: 14 November 2021 \\ (c) The Author(s), under exclusive licence to Springer Science+Business Media, LLC, part of Springer Nature 2021
}

\begin{abstract}
Health-Risk Behaviours (HRBs) are significant antecedent conditions of adverse health outcomes among adolescents, and their prevention requires an in-depth understanding of associated factors. Like any other behaviour, HRBs may be an outcome of a complex interplay between personal and situational factors that determines our responses. Among other factors, emotional tendencies, specific behavioural patterns, and psychosocial environment may be the significant factors working at different hierarchical positions within a system and guiding human behaviours, including HRBs. Previous studies have explored the role of these specific factors in developing and maintaining HRBs, but mainly among the adult population, and no conclusive results could be observed regarding their contribution to HRBs in adolescents. The present study explored the predictability of adolescents' engagement in HRBs with regard to three representations of the mentioned factors, i.e., emotion regulation difficulties, perceived parenting practices and personality traits. A total of 723 (Males $=440$ ) adolescents $\left(\mathrm{M}_{\mathrm{age}}=16.05, S D=1.1\right)$ provided relevant information on the standardized questionnaires. Structural equation modelling was applied to test the stated hypotheses. Analysis revealed that the adolescents who reported more difficulty regulating one's emotions, perceived parenting practice as maladaptive, scored high on neuroticism and low on conscientiousness, showed more engagement in HRBs than their counterparts. Further, the findings indicated that emotion regulation difficulties and perceived parenting practices are stronger predictors of HRBs than personality traits. Interventional programs targeting HRBs among adolescents should address specific facets of emotional dysregulation and sensitise parents about their role in moderating adolescents' HRBs.
\end{abstract}

Keywords Health-risk behaviours $\cdot$ Emotion regulation difficulties $\cdot$ Parenting $\cdot$ Personality $\cdot$ Adolescents

Health-Risk Behaviours (HRBs) have become the leading cause of mortality among adolescents, especially in low and middle-income countries (Weiss \& Ferrand, 2019). In 2019, more than 1.5 million deaths of persons within 10-24 years of age were reported; most of these were primarily due to preventable or treatable causes, including HRBs (World Health Organization, 2021). In the Indian context, previous studies claimed that about 10-30 per cent of young people engage in health impacting behaviours, such as poor diet, sedentary lifestyle, violence, unsafe sexual practices and risky behaviours on roads (Sunitha \& Gururaj, 2014). In order to prevent adverse health outcomes among adolescents, the underlying dynamics of adolescence age,

Parwinder Singh

singh_parwinder@iitrpr.ac.in

1 Department of Humanities and Social Sciences, Indian Institute of Technology Ropar, Rupnagar, Punjab, India the causal mechanism of health-promoting behaviours and HRBs need to be understood. Among the mentioned aspects, the present paper focuses on the dynamics of HRBs. Steptoe (2007) defined health risk behaviour as any behaviour that increases the risk of disease or injury, with or without the awareness of the link between the behaviour and the risk (Steptoe, 2007). HRBs include addictive behaviours, externalising behaviours (e.g., violence, self-harm), unsafe sexual activities, sedentary lifestyle and unhealthy dietary behaviours (Underwood et al., 2020).

Similar to other behaviours, HRBs may be an outcome of a complex interplay between personal and situational factors. The problem behaviour theory (Donovan et al., 1993) supports the assertion and maintains that any maladaptive behaviour is an outcome of imbalance among various risk and protective factors, broadly related to personality (e.g., temperament, values, beliefs), psychosocial environment (e.g., family and peer expectations) and behavioural domain, 
including its subsystem of emotion. Another model (Glanz et al., 2015) emphasizes a dynamic interaction among cognitive, behavioural, and environmental factors that influences HRBs. Understanding of risk and protective factors at multiple levels may facilitate intervention programmes targeting HRBs (Glanz et al., 2015). Similarly, an integrative model of adolescents' health risk behaviour (Keeler \& Kaiser, 2010) also advocated for a multi-dimensional understanding of HRBs to prevent HRBs among adolescents. Knowledge about the dynamics of associated factors would facilitate interventional planning to reduce adolescents' engagement in HRBs. While considering the mentioned models and their suggestions, the present study was designed to study three variables representing the mentioned three domains suggested by the problem behaviour theory. The present study explored the role of emotion regulation difficulties, perceived parenting practices and personality traits in developing and maintaining HRBs. As per the existing literature on HRBs, the factors have been explored but mainly individually, and most of the studies explored more severe forms of HRBs among the adult population (Bailey et al., 2019; Bozzini et al., 2020). No conclusive results could be observed regarding the dynamics of HRBs among adolescents. The present study's findings may contribute to the fundamental understanding of the HRBs in the Indian context. Not many studies have empirically explored the role of culture on specific HRBs; however, the available studies suggested that culture plays an important role in regulating health-related behaviours (Hamzah et al., 2018; Napier et al., 2014), and an individual's cultural context is essential for changing HRBs (Kaplan, 2014; Higgins, 2014). Adolescence, a time of transition and considerable biological, cognitive, and socio-emotional advances, is culturally variable like all stages of human development (Gibbons \& Poelker, 2019; UNICEF, 2011); therefore, before theorizing about HRBs, the cultural context of the population should be considered.

Though adolescence is characterized by a general higher risk-taking tendency (Smith et al., 2014; van den Bos \& Hertwig, 2017), not all adolescents indulge in HRBs. Unique risk and protective factors, with their interactions, may make individuals more or less vulnerable to HRBs (Jessor, 1991). In the present study, one of the dynamic relationship patterns among emotion regulation difficulties, perceived parenting practices, personality and HRBs was explored, which may help understand the individual differences in the vulnerabilities for HRBs in Indian adolescents. Though a few previous studies support the model proposed, a few gaps motivated us to conduct the study. Most importantly, the studies conducted so far explored the role of emotional regulation and personality traits mainly among the adult population; therefore, no conclusive evidence is available regarding the predictability of adolescents' HRBs with regard to these three factors. Secondly, most studies investigated severe HRBs, such as drug or alcohol abuse and unsafe sexual practices. Not many studies looked into other, less severe but highly prevalent, HRBs such as risky driving, self-harm, dietary $\&$ physical exercise and medication adherence. Thirdly, the previous studies' samples were mainly drawn from western, educated, industrialized, affluent, and democratic societies (Nielsen et al., 2017) and general theories were proposed without considering substantial variability across different cultures. Research has shown that the expression of emotions and the acceptance of emotional expression in societies vary across cultures. For instance, in a collectivistic culture like India, the expression of negative emotions is less appreciated due to various sociological reasons, and also parents tend to cultivate conformity in their children, which affects their emotional development (Chadda \& Deb, 2013; Hapunda et al., 2019). In the context of parenting also, cultures do impact the values children acquire through parenting. For instance, in India, importance is given to families' solid hierarchical kinship structure, emphasising obedience to the authority (Sondhi, 2017). Such values may further impact the engagement in socially forbidden HRBs. Thus, in that case, the role of perceived parenting practices must be explored in HRBs in all types of cultures. Moreover, In the Indian context, previous studies claimed that about 10-30 per cent of young people engage in health impacting behaviours, such as poor diet, sedentary lifestyle, violence, unsafe sexual practices and risky behaviours on roads (Sunitha \& Gururaj, 2014). The existing scenario demands the immediate attention of researchers and policymakers to explore the mechanism and intervene. Despite the higher prevalence and severity of HRBs among Indian adolescents, only a few studies explored the relationship among emotion-regulation difficulties, personality and the perception of parenting practices and adolescents' engagement in HRB; therefore, the phenomenon needs to be explored. Most Indian studies we came across focused on the prevalence of HRBs and related socio-economic factors (e.g., Ghule \& Donta, 2011; Kumar et al., 2007; Narain et al., 2011; Dhavan et al., 2009). In the Indian context, no study, as per our best knowledge, explored the predictability of HRBs with regard to the three domains we explored in the present study.

\section{Emotion Regulation and HRBs}

Among other potential factors, the malfunctioning emotions may impact adolescents' engagement in HRBs. Emotions initiate and guide our behaviour, and the emotion regulation process mainly determines which emotions one has and how one expresses these emotions to achieve a desirable goal (Gross, 2015). Effective emotion regulation requires skills, such as recognizing one's emotional state, identifying affect 
in others and using strategies for modulating one's emotional response. When a person lacks the skills or fails to execute the skills appropriately, emotions become less effective, and instead of motivating adaptive behaviour, it may lead to maladaptive behaviours, including HRBs. Findings indicate that among the adult sample, deficits in emotion regulation may induce distress, dysregulation of which further drive individuals to engage in HRBs such as drug abuse, alcohol abuse, sexual risk behaviours, bullying, aggressive behaviours, unhealthy dietary behaviours, addictive behaviours, unintentional injuries or violence-related behaviours, suicidal behaviours, and lack of medical adherence (Garofalo \& Velotti, 2017; Lansing et al., 2019; Ram et al., 2018; Weiss et al., 2015; Zafar et al., 2021).

Research has demonstrated that when people experience high levels of negative emotion and resulting distress, they act impulsively in an attempt to decrease this distress, prioritizing short-term soothing activities like risky driving and poor dieting, over other effective strategies (Al-Musharaf, 2020; Hayley et al., 2017; Haynos \& Fruzzetti, 2011; Tice et al., 2001; Trógolo et al., 2014). These behaviours may represent an attempt to improve or avoid negative emotions (Berking et al., 2008).

Researchers also explored different types of specific difficulties that individuals may experience while regulating ones' emotions. The difficulties that cause emotional disturbance are mainly related to understanding and acceptance of emotions, the ability to refrain from impulsive behaviours, the utilization of adaptive ways to regulate the intensity and duration of emotional responses, and the ability to use effective emotional regulation strategies (Gratz \& Roemer, 2004). Individuals having deficits in any of these areas may cause dysfunctional emotions. Further, in order to deal with dysfunctional emotions, individuals may indulge in health-compromising behaviours mistakenly perceived as stress-relieving, such as smoking and alcohol use (Gratz \& Roemer, 2004).

\section{Parenting and HRBs}

Family environmental factors have been linked to HRBs (Liu, 2019; Gutman and Feinstein, 2010; Prino et al., 2016; Margolis et al., 2020), and among the factors, the role of parenting has been mainly emphasized (Sleddens et al., 2011). The primary socialization theory (PST; Francis \& Thorpe, 2010; Oetting \& Donnermeyer, 1998) suggests that HRBs are learned in social contexts and influenced by the nature of interaction with parents and peers. The theory postulates that parental monitoring and involvement significantly impact adolescents' indulgence in health-compromising behaviours (Francis \& Thorpe, 2010). The specific parenting behaviours that influence adolescents' health behaviours include the type of discipline (consistent versus inconsistent), level of parental involvement, level of parental monitoring, type of communication (Alloy et al., 2006; Pengpid \& Peltzer, 2020; Wang, 2014) and parenting style (Baumrind, 1991; Hardie, 2021). Not many studies explored the relation between general parenting behaviours and HRBs; however, in the available studies, general parenting practices significantly predicted various HRBs like alcohol use (Ryan et al., 2010), smoking (Harakeh et al., 2010) and delay of sexual debut (de Graaf et al., 2011). However, some other studies could not observe any association between parenting practices and HRBs (Blissett \& Haycraft, 2008; Florenzano et al., 2011). Literature also suggests that the relationship between the perception of such parenting practices and adolescents' engagement in comparatively less severe but more prevalent HRBs (e.g., risky driving, self-harm, indulgence in violent behaviours, unhealthy dietary behaviours, physical inactivity and medication adherence) is less explored. Thus, the role of parenting practices in developing and maintaining HRBs is not conclusive and need more exploration; the present study aims to provide empirical evidence for the association between the nature of perceived parenting and engagement in HRBs.

\section{Personality and HRBs}

Psychologists have been trying to understand personality dynamics for a long; however, its importance for developing HRBs among adolescents is still not evident. In this study, two personality traits, i.e., neuroticism and conscientiousness, were explored. Previous studies found a significant association between these factors and HRBs among adults (Graham et al., 2017, 2020). The present study explored whether similar relationships exist among adolescents also. Neuroticism has substantial predictive utility for several mental health (Fanous et al., 2007) and physical health problems (Malouff et al., 2005; Smith \& MacKenzie, 2006). Similarly, conscientiousness was also found to be associated with HRBs (Bogg \& Roberts, 2004). Researchers have also observed the moderating effect of conscientiousness for the neuroticism-HRBs link (Turiano et al., 2012; Weston \& Jackson, 2015; Weston et al., 2018). Findings suggested that individuals high on neuroticism and low on conscientiousness indulge more in HRBs than individuals high on both (Vollrath \& Torgersen, 2002). Literature on neuroticism mentions a debate on the phenomenon of 'Healthy Neuroticism' (Friedman, 2000), which maintains that neuroticism, while often not good for health, could be beneficial in some circumstances. This assertion is still debatable, and previous studies have not found any consistent effects of healthy neuroticism on health outcomes (Weston et al., 2020). More research is required to clarify the role neuroticism plays, and 
the present study may also shed some light on the phenomenon of 'Healthy Neuroticism'.

\section{The Present Study}

Considering the growing prevalence of HRBs among adolescents, specifically Punjabi adolescents (Dandona et al., 2018), and the mentioned gaps, an attempt was made to establish emotion regulation difficulties, perceived parenting practices and two personality traits as predictors of HRBs among adolescents. More specifically, the present study is an effort to explore the predictive relationship between adolescents' engagement in HRBs, i.e., risky driving, self-harm, violence, unhealthy dietary behaviours, poor medication adherence, and physical inactivity, and (1) emotion regulation difficulties (2) perceived parenting practices, i.e., perceived positive and negative parenting (3) neuroticism and (4) conscientiousness. Based on the literature review, it was hypothesized that the model would significantly explain the variance in HRBs; emotion regulation difficulties would predict studied HRBs positively(H1); perceived positive parenting would predict HRBs negatively(H2); perceived negative parenting would predict these behaviours positively(H3); neuroticism would predict HRBs positively(H4), and there would be a negative association between conscientiousness and $\mathrm{HRBs}(\mathrm{H} 5)$.

\section{Method}

\section{Sample}

This study's sample consists of 723 (Males $=440$ ) adolescents in the age group of $14-18$ years $\left(\mathrm{M}_{\mathrm{age}}=16.05\right.$, $\mathrm{SD}=1.1)$. The participating students were studying in Grades 9-12 and selected from twenty schools located in the Indian state of Punjab. In the present COVID-19 crisis, the relevant information was obtained using online forms. Out of 800 participants selected for the study, only 723 responses were included for data analysis; a few participants did not consent, and some did not complete the questionnaires. The distribution of participants in terms of sex, class, and locality is given in Table 1.

\section{Measures}

The Youth Risk Behaviour Survey Questionnaire (YRBSQ; Centre for Disease Control \& Prevention, 2019), Difficulties in Emotion Regulation Questionnaire (Gratz \& Roemer, 2004), The Alabama Parenting Questionnaire (APQ-Child Form; Frick, 1991) and NEO-FFI (Costa \& McCrae, 1992) were used in the current study. The questionnaires were used in their original form except for the YRBSQ. A few questions in YRBSQ were not considered appropriate for the Indian population and were removed as per the suggestions of the institute's ethics committee. Items of other questionnaires were considered appropriate for Indian culture. In order to rule out any language-related biases, the participants were initially asked about their English language proficiency, especially in reading and comprehension. As most of the participants(students) were receiving their class instructions in the English language for at least five years, they showed no difficulty understanding questions given in the English language.

\section{Youth Risk Behaviour Survey Questionnaire}

The Youth Risk Behaviour Survey Questionnaire (YRBSQ; Centre for Disease Control \& Prevention, 2019) was used to assess adolescents' indulgence in HRBs. The original YRBSQ contained 89 items; however, in the present study, 37 items were used to assess selected HRBs, i.e., risky driving, self-harm, violence, poor medication adherence, unhealthy dietary behaviours and physical inactivity. Higher scores on each type indicate a higher indulgence in the risk behaviours. As all these behaviours are related to one broad dimension of poor self-care, scores on different HRBs were added to get a composite score representing overall engagement in HRBs. Lima et al. (2020), in a study on a large sample, found satisfactory psychometric properties of this questionnaire; Cronbach's alpha was 0.77 for the overall scale, and the intraclass correlation coefficient between different domains were more than 0.75 . In the present study, the Cronbach alpha for the total score was 0.73 , and domain-wise it ranged from 0.69 to 0.78 . Some representative items of the questionnaire are: "During the past 30 days, how many times did you drive/ride a car/scooter or another vehicle faster than the prescribed speed limit"; "During the past seven days, on how many days were you physically active for a total of at least 60 min per day?"; "During the past seven days, on how many days did you eat meals on time?".

\section{Difficulties in Emotion Regulation Questionnaire}

Difficulties in Emotion Regulation Questionnaire (Gratz \& Roemer, 2004) is a 36-item self-report measure that assesses individuals' experience of six emotion regulation difficulties, namely, difficulties engaging in goal-directed behaviours when distressed, non-acceptance of emotional responses, lack of emotional awareness, difficulties controlling impulsive behaviours when distressed, lack of emotional clarity, and limited access to emotion regulation strategies. Participants are asked to indicate how often the items apply to them, with responses ranging from 'almost never' to 'almost always'. The total score ranges from 36-180, and the higher 
Table 1 Demographic characteristics of the sample and descriptive statistics

\begin{tabular}{|c|c|c|c|c|c|c|c|c|}
\hline Demographic characteristics & $\mathrm{N}$ & $\%$ age & Min & $\operatorname{Max}$ & Mean & SD & Skew & Kurt \\
\hline Age (Years) & 723 & & 14 & 18 & 16.05 & 1.10 & -0.17 & -0.76 \\
\hline \multicolumn{9}{|l|}{ Gender } \\
\hline Male & 440 & 60.9 & & & & & & \\
\hline Female & 283 & 39.1 & & & & & & \\
\hline \multicolumn{9}{|l|}{ Education } \\
\hline 9th & 118 & 16.3 & & & & & & \\
\hline 10 th & 183 & 25.3 & & & & & & \\
\hline 11th & 210 & 29.0 & & & & & & \\
\hline 12 th & 212 & 29.3 & & & & & & \\
\hline \multicolumn{9}{|l|}{ Locality } \\
\hline Rural & 352 & 48.7 & & & & & & \\
\hline Urban & 371 & 51.3 & & & & & & \\
\hline \multicolumn{9}{|l|}{ Family Type } \\
\hline Nuclear & 414 & 57.3 & & & & & & \\
\hline Joint & 309 & 42.7 & & & & & & \\
\hline Engagement in Health-Risk Behaviours & & & 2 & 21 & 6.03 & 4.16 & 1.51 & 2.84 \\
\hline Non-Acceptance of Emotional Responses & & & 6 & 30 & 15.94 & 6.29 & 0.28 & -0.79 \\
\hline Difficulty Engaging in Goal-Directed Behaviour & & & 5 & 25 & 15.60 & 4.69 & -0.10 & -0.53 \\
\hline Impulse Control Difficulties & & & 6 & 30 & 15.62 & 5.97 & .032 & -0.74 \\
\hline Lack of Emotional Awareness & & & 6 & 30 & 14.29 & 4.57 & 0.60 & 0.39 \\
\hline Limited Access to Emotion Regulation Strategies & & & 8 & 40 & 20.74 & 7.37 & 0.28 & -0.65 \\
\hline Lack of Emotional Clarity & & & 5 & 25 & 11.84 & 4.39 & 0.37 & -0.34 \\
\hline Overall Emotion Regulation Difficulties & & & 37 & 165 & 94.03 & 24.07 & 0.22 & -0.38 \\
\hline Perceived Mother Involvement & & & 10 & 50 & 35.28 & 8.64 & -0.26 & -0.64 \\
\hline Perceived Father Involvement & & & 9 & 45 & 28.78 & 8.65 & -0.24 & -0.57 \\
\hline Positive Parenting Practices & & & 6 & 30 & 22.37 & 5.77 & -0.59 & -0.41 \\
\hline Overall Positive Parenting & & & 28 & 125 & 86.42 & 20.88 & -0.29 & -0.65 \\
\hline Poor Monitoring by Parents & & & 10 & 48 & 21.27 & 7.64 & 0.76 & 0.20 \\
\hline Inconsistent Discipline & & & 6 & 30 & 15.62 & 4.32 & 0.32 & 0.02 \\
\hline Corporal Punishments & & & 3 & 15 & 7.24 & 2.94 & 0.49 & -0.37 \\
\hline Other Maladaptive Parenting Practices & & & 7 & 35 & 14.69 & 4.93 & 1.15 & 1.22 \\
\hline Overall Negative Parenting & & & 29 & 124 & 58.82 & 16.02 & 1.05 & 1.14 \\
\hline Neuroticism & & & 14 & 60 & 35.74 & 6.11 & 0.01 & 1.40 \\
\hline Conscientiousness & & & 20 & 59 & 42.00 & 5.71 & -0.21 & 0.65 \\
\hline
\end{tabular}

scores indicate more difficulties in emotion regulation. In terms of reliability, the overall DERS score and the subscale scores have been found to have high internal consistency (Hallion et al., 2018). In the present study, a summated score of all 36 items was used to measure overall emotion regulation difficulties, and the Cronbach alpha came out to be 0.91 .

\section{Alabama Parenting Questionnaire}

The Alabama Parenting Questionnaire (APQ-Child Form; Frick, 1991) consists of 42 items, each rated on a 5-point scale ranging from 1 (never) to 5 (always). It measures five dimensions of parenting: (1) Involvement (1A. Mother Involvement and 1B. Father Involvement), (2) Positive Parenting (3) Poor Monitoring, (4) Inconsistent Discipline (5) use of Corporal Punishment. Internal consistencies ranged from 0.47 (Corporal Punishment) to 0.81 (Positive involvement), and satisfactory construct validity has also been observed in the previous studies (Zlomke et al., 2014). The subscale scores calculated as per the manual were used in correlational and regression analysis; however, for structural equation modelling, latent variables of positive and negative sub-scales were used as exogenous latent variables.

\section{The NEO Five-Factor Inventory}

The NEO five-factor inventory (NEO-FFI) (Costa \& McCrae, 1992) was used to measure adolescents' personality characteristics. The NEO-FFI, a 60-item inventory, measures five domains of personality, i.e., Neuroticism, Extraversion, 
Openness, Agreeableness, and Conscientiousness. Each subscale includes 12 self-descriptive statements given on a 5-point Likert-type scale ranging from 'strongly disagree' to 'strongly agree'. The reliability and validity of the inventory have been established in previous studies conducted across the cultures; Cronbach-alpha in most of the studies ranged from 0.68 to 0.85 (Sherry et al., 2007). In the present study, only two scales of the inventory, i.e., neuroticism and conscientiousness, were used, and the Cronbach alphas for both the subscales were 0.78 and 0.80 , respectively.

\section{Procedure}

After preparing the required questionnaire set, the researcher conducted a statistical power analysis to estimate the required sample size. Based on the effect sizes mentioned in previous studies, a small effect size of 0.15 (Cohen, 1988) was expected. With an alpha $=0.01$, power $=0.80$, and for a small effect size, a sample of a minimum of 645 was sufficient (Cohen, 1992). Thus, the sample size of the present study $(\mathrm{N}=723)$ was adequate for the purpose. The research proposal was then submitted to the Institute Ethics Committee (Human); the committee approved the same through letter no. IEC/11/2019. In the present study, multistage stratified random sampling was used to select participants. Five districts out of twenty-three districts in Punjab, namely, Bathinda, Patiala, Ropar, Jalandhar and Gurdaspur, were selected randomly. Then the researcher contacted district education officers (DEOs), and lists of schools were obtained. Out of 323 schools in the lists, 100 schools (20 schools from each selected district) were randomly selected; schools' authorities were contacted and provided detailed information about the project. Based on the responses, four schools from each district were finally shortlisted. The school authorities provided the contact details of the parents, and then the parental consent form, including all the required information, was sent to the parents. After receiving parents' consent, participants were asked to provide the relevant information on the standard questionnaires. Out of 800 selected respondents, only 723 responses were included for the analysis; the rest were excluded considering incomplete responses, scores on a few control items, age and extreme responses. A few controlled items were inserted in the questionnaire to check whether participants read all the questions correctly. One such Likert-scale item was 'I have seen a three-headed elephant. Another factor, i.e., prior communication regarding the feedback to be provided by trained psychologists after the assessment, helped us motivate participants to provide high-quality responses. All participants were provided with personalized feedback and some suggestions to manage emotion regulation difficulties.

In order to test the stated hypotheses, obtained data was cleaned and subjected initially to correlational and regression analysis using IBM SPSS 25.0. The regression analysis explored the predictability of HRBs with regard to emotion regulation difficulties, positive parenting, negative parenting, neuroticism and conscientiousness, controlling the effect of age and gender. Additionally, Structural Equation Modeling was done using item-parcels to test the goodness of the model fit. In the analysis, out of five predictors, three predictors were used as latent exogenous variables. Scores on neuroticism and conscientiousness were taken as observed exogenous variables.

\section{Results}

The findings are summarized in Table 1 to Table 6. Table 1 shows the demographic characteristics of the sample. Overall descriptive statistics and correlation coefficients are given in Table 2. As shown, significant correlation coefficients have been observed among HRBs and scores on emotion regulation difficulties, $r(723)=0.43, p<0.01$, positive parenting, $r(723)=-0.33, p<0.01$, negative parenting, $r$ $(723)=0.25, p<0.01$, neuroticism, $r(723)=0.26, p<0.01$ and conscientiousness, $r(723)=-0.17, p<0.01$. Individuals who reported more difficulties regulating one's emotions, dysfunctional/negative parenting practices in their family, high neuroticism and low conscientiousness showed more indulgence in HRBs.

Table 2 Descriptive statistics and correlation coefficients among scores on neuroticism, conscientiousness and health-risk behaviours

\begin{tabular}{|c|c|c|c|c|c|c|c|c|c|}
\hline & Variables & M & SD & 1 & 2 & 3 & 4 & 5 & 6 \\
\hline 1 & Engagement in Health-Risk Behaviours & 6.03 & 4.16 & - & & & & & \\
\hline 2 & Emotion Regulation Difficulties & 94.03 & 24.07 & $0.43 * *$ & - & & & & \\
\hline 3 & Positive Parenting & 86.42 & 20.88 & $-0.33 * *$ & $-0.31 * *$ & - & & & \\
\hline 4 & Negative Parenting & 58.82 & 16.02 & $0.25 * *$ & $0.30 * *$ & 0.07 & - & & \\
\hline 5 & Neuroticism & 35.74 & 6.11 & $0.26^{* *}$ & $0.37 * *$ & $-0.22 * *$ & $0.09 *$ & - & \\
\hline 6 & Conscientiousness & 42.00 & 5.71 & $-0.17 * *$ & $-0.32 * *$ & $0.30 * *$ & $-0.16^{* *}$ & $-0.48 * *$ & - \\
\hline
\end{tabular}

$\mathrm{N}=723, * \mathrm{p}<0.05, * * \mathrm{p}<0.01$ 
As depicted in Table 3, emotion regulation difficulties significantly predicted engagement in HRBs, $\beta=0.28$, $t(715)=7.13, p<0.001$, therefore confirming the first hypothesis of the study about the predictive effect of emotion regulation difficulties (H1). Perceived positive parenting also predicts indulgence in HRBs significantly, $\beta=-0.24$, $t(715)=6.89, p<0.001$, therefore confirming the second hypothesis of the study about the predictive effect of perceived positive parenting (H2). Similarly, perceived negative parenting also predicts engagement in HRBs significantly, $\beta=0.18, t(715)=4.99, p<0.001$, confirming the third hypothesis of the study about the predictive effect of perceived negative parenting (H3). Neuroticism has also been found to be a significant predictor of HRBs, $\beta=0.13$, $t(715)=3.53, p<0.001$, therefore confirming the fourth hypothesis of the study. Regarding the fifth hypothesis, i.e., the predictive effect of conscientiousness, the suppression effect was observed. Conscientiousness was negatively correlated with HRBs, $r(723)=-0.17, p<0.01$ (Table 2), however in the regression model, it came out to be a positive predictor of the same, $\beta=0.08, t(715)=2.18, p<0.05$. Further exploration indicated that the suppression occurred mainly in the presence of emotion-regulation difficulties. The regression coefficient of conscientiousness, $\beta=-0.17$, $p<0.01$, significantly reduced, $\beta=-0.03, p>0.05$, when emotion regulation difficulties were added in the model. Not much difference was observed when other predictors were tested similarly. The overall variance in HRBs explained by the five predictors has been found to be statistically significant, $R^{2}$ (change) $=0.26, F(7,715)=51.31, p<0.01$, Cohen $f^{2}=0.35$. The studied predictors explain $26 \%$ of the variance in HRBs. When all the predictors were included in the equation, the minimum tolerance and highest variance inflation ratio (VIF) were between 0.675 and 1.48 , respectively. Thus, multicollinearity was not a severe issue in the analysis. Also, all predictors were found to be linearly related to engagement in HRBs.

In order to confirm the validity of composite scores calculated for the scales having multiple dimensions, e.g., emotion regulation difficulties, the proposed model was tested through structural equation modelling also using IBM AMOS 25.0. We chose maximum likelihood estimation, and input data were the item-parcel scores on Likert-type questionnaires. Except for personality trait scores, exogenous latent variables were used to predict indulgence in HRBs. We hypothesized a one-factor model for each construct, to be confirmed in the measurement portion of the model. The assumptions of multivariate normality and linearity were tested using IBM SPSS 25.0 and found satisfactory. The final sample size was 723(17.2 participants to one parameter estimated); there were no missing data. The goodness-of-fit indexes are presented in Table 4. As shown, the values obtained pertaining to the Goodness of Fit Index, the Comparative Fit Index, the Tucker-Lewis fit Index, the Squared Root Mean Residual, and the Root Mean Squared Error of Approximation are found to be acceptable for the given sample size and the numbers of observed variables (Hairs et al., 2009), $G F I=0.94, C F I=0.94, T L I=0.92$, $S R M R=0.05$, RMSEA $=0.07$. These values indicate a near to good fit between the model and the observed data. Parameter estimated in the measurement models, along with reliability indices, are presented in Table 5. Table 6 presents the parameters estimated in the structural model of HRBs and effect size estimates. Standardized parameter estimates are also depicted in Fig. 1. The findings support the model proposed and all the hypotheses, except H5. Table 6 also

Table 3 Regression analysis summary for health-risk behaviour scores (criterion variable) with age \& gender as control variables, and observed scores on emotion regulation difficulties, positive parenting, negative parenting, neuroticism \& conscientiousness as predictors

\begin{tabular}{|c|c|c|c|c|c|c|c|c|c|c|}
\hline \multirow{2}{*}{\multicolumn{2}{|c|}{$\begin{array}{l}\text { Effect } \\
\text { (Ordered Predictors) }\end{array}$}} & \multicolumn{3}{|c|}{ Estimates } & \multicolumn{2}{|c|}{$95 \% \mathrm{CI}$} & \multirow[t]{2}{*}{$\mathrm{R}^{2}$} & \multirow[t]{2}{*}{$\mathrm{R}^{2}$ Change } & \multirow[t]{2}{*}{ F-Change } & \multirow[t]{2}{*}{ Cohen $\mathrm{f}^{2}$} \\
\hline & & B & SE & $\beta$ & LL & UL & & & & \\
\hline \multicolumn{2}{|c|}{ Intercept } & -4.38 & 2.14 & & & & & & & - \\
\hline \multirow[t]{2}{*}{1} & Age & 0.30 & 0.10 & $0.10 * *$ & -0.10 & 0.30 & 0.01 & - & - & - \\
\hline & Gender & 0.08 & 0.24 & 0.01 & -0.46 & 0.48 & & & & \\
\hline \multirow[t]{5}{*}{2} & $\begin{array}{l}\text { Emotion Regulation } \\
\text { Difficulties }\end{array}$ & 0.04 & 0.01 & $0.28 * *$ & 0.26 & 0.30 & $0.27^{\mathrm{a}}$ & 0.26 & $51.31 * *$ & $0.35^{\mathrm{b}}$ \\
\hline & Positive Parenting & -0.04 & 0.01 & $-0.24 * *$ & -0.26 & -0.22 & & & & \\
\hline & Negative Parenting & 0.04 & 0.01 & $0.18 * *$ & 0.16 & 0.20 & & & & \\
\hline & Neuroticism & 0.07 & 0.02 & $0.13 * *$ & 0.09 & 0.17 & & & & \\
\hline & Conscientiousness & 0.05 & 0.02 & $0.08 *$ & 0.04 & 0.12 & & & & \\
\hline
\end{tabular}

$\mathrm{N}=723$, B- Unstandardized coefficients

${ }^{*} \mathrm{p}<0.05, * * \mathrm{p}<0.01$,

${ }^{\mathrm{a}}$ Cumulative $\mathrm{R}^{2}$

${ }^{b}$ Large effect size (Cohen, 1988), excluding $\mathrm{R}^{2}$ of age and gender 
Table 4 The goodness of fit indices

\begin{tabular}{lll}
\hline Index & $\begin{array}{l}\text { Accepted Values for } \mathrm{N}=723(\mathrm{~N}>250) \text { and Observed } \\
\text { Variables }=17(12<\mathrm{OVs}<30)\end{array}$ & Model Results \\
\hline $\begin{array}{l}\text { Normed Chi-Square (Chi- } \\
\text { square/DF) }\end{array}$ & $3<$ Chi-square/DF $<5$ (Significant p-values expected) & 4.69 \\
GFI & Above 0.92\# & 0.94 \\
CFI & Above 0.92\# & 0.94 \\
TLI & Above 0.92\# & 0.92 \\
SRMR & Below 0.08\# & 0.05 \\
RMSEA & Below 0.08\# & 0.07 \\
\hline
\end{tabular}

\#as mentioned in Hairs et al. (2009)

Table 5 Parameters estimated in the measurement model

\begin{tabular}{|c|c|c|c|c|}
\hline Latent Variables & Observed Variables & Path Coefficients & $\begin{array}{l}\text { Composite Reli- } \\
\text { ability }\end{array}$ & $\begin{array}{l}\text { Average } \\
\text { Variance } \\
\text { Explained }\end{array}$ \\
\hline \multirow{5}{*}{$\begin{array}{l}\text { Emotion Regulation Dif- } \\
\text { ficulties }\end{array}$} & Non-Acceptance of Emotional Responses & $0.77 * *$ & \multirow[t]{5}{*}{0.88} & \multirow[t]{5}{*}{0.59} \\
\hline & Difficulty Engaging in Goal-Directed Behaviour & $0.69 * *$ & & \\
\hline & Impulse Control Difficulties & $0.82 * *$ & & \\
\hline & Limited Access to Emotion Regulation Strategies & $0.90 * *$ & & \\
\hline & Lack of Emotional Clarity & $0.62 * *$ & & \\
\hline \multirow[t]{3}{*}{ Positive Parenting } & Perceived Mother Involvement & $0.92 * *$ & \multirow[t]{3}{*}{0.89} & \multirow[t]{3}{*}{0.74} \\
\hline & Perceived Father Involvement & $0.79 * *$ & & \\
\hline & Positive Parenting Practices & $0.86^{* *}$ & & \\
\hline \multirow[t]{4}{*}{ Negative Parenting } & Poor Monitoring by Parents & $0.77 * *$ & \multirow[t]{4}{*}{0.80} & \multirow[t]{4}{*}{0.51} \\
\hline & Inconsistent Discipline & $0.68 * *$ & & \\
\hline & Corporal Punishments & $0.66 * *$ & & \\
\hline & Other Maladaptive Parenting Practices & $0.72 * *$ & & \\
\hline
\end{tabular}

$\mathrm{N}=723$,

*** $\mathrm{p}<0.01$,

shows that the five exogenous variables explain $29 \%$ of the variation in health-risk behaviour entered in the model, a statistically significant contribution with large effect size, $R^{2}=0.29, p<0.01$, Cohen $f^{2}=0.41$.

\section{Discussion}

The current study mainly proposed and tested a model of indulgence in HRBs among adolescents in which predictive efficacy of emotion regulation difficulties, perceived parenting practices, neuroticism and conscientiousness was investigated. Based on the literature review, we predicted significant associations among studied predictors and HRBs and expected all to contribute significantly to the variance in HRBs. As hypothesized, the model shows statistical significance and fits well with the data. The observed data support all the specific hypotheses, except H5. Emotion regulation difficulties, perceived parenting practices, neuroticism and conscientiousness, are significantly associated with the engagement in HRBs and are significant predictors of the same. Individuals who reported more difficulties regulating their emotions, more negative parenting practices and less positive ones in their family, high neuroticism and low conscientiousness, scored more on HRBs. Collectively these variables explain $29 \%$ of the variance in HRBs' scores. An interesting finding has also been observed in the regression analysis; the effect of conscientiousness was significantly suppressed in the presence of emotion regulation difficulties. Further exploration may suggest the mediational effect of emotion regulation difficulties in the relationship between conscientiousness and HRBs. Emotion regulation difficulties emerged as the strongest variable that affects the engagement in HRBs and limits the beneficial effect of conscientiousness on HRBs.

The present findings extend support to the previous studies showing a significant relationship between studied predictors and HRBs (Bogg \& Roberts, 2004; Francis \& 
Table 6 Parameters estimated in the structural model for health-risk behaviours

\begin{tabular}{|c|c|c|c|c|c|c|}
\hline Observed Predictors & Latent Predictors & B & SE & $\beta$ & $\mathrm{R}^{2}$ & Cohen $\mathrm{F}^{2}$ \\
\hline $\begin{array}{l}\text { Non-Acceptance of Emotional Responses } \\
\text { Difficulty Engaging in Goal-Directed Behaviour } \\
\text { Impulse Control Difficulties } \\
\text { Limited Access to Emotion Regulation Strategies } \\
\text { Lack of Emotional Clarity }\end{array}$ & $\begin{array}{l}\text { Emotion Regulation } \\
\text { Difficulties }\end{array}$ & 0.18 & 0.02 & $0.28 * *$ & 0.29 & $0.41^{\mathrm{a}}$ \\
\hline $\begin{array}{l}\text { Perceived Mother Involvement } \\
\text { Perceived Father Involvement } \\
\text { Positive Parenting Practices }\end{array}$ & Positive Parenting & -0.18 & 0.02 & $-0.28 * *$ & & \\
\hline $\begin{array}{l}\text { Poor Monitoring by Parents } \\
\text { Inconsistent Discipline } \\
\text { Corporal Punishments } \\
\text { Other Maladaptive Parenting Practices }\end{array}$ & Negative Parenting & 0.32 & 0.06 & $0.20 * *$ & & \\
\hline Neuroticism & - & 0.06 & 0.02 & $0.11 * *$ & & \\
\hline Conscientiousness & - & 0.05 & 0.02 & $0.09 *$ & & \\
\hline
\end{tabular}

$\mathrm{N}=723$, B- Unstandardized coefficients

* $\mathrm{p}<0.05, * * \mathrm{p}<0.01$,

${ }^{\text {a }}$ Large effect size (Cohen, 1988), excluding $\mathrm{R}^{2}$ of age and gender

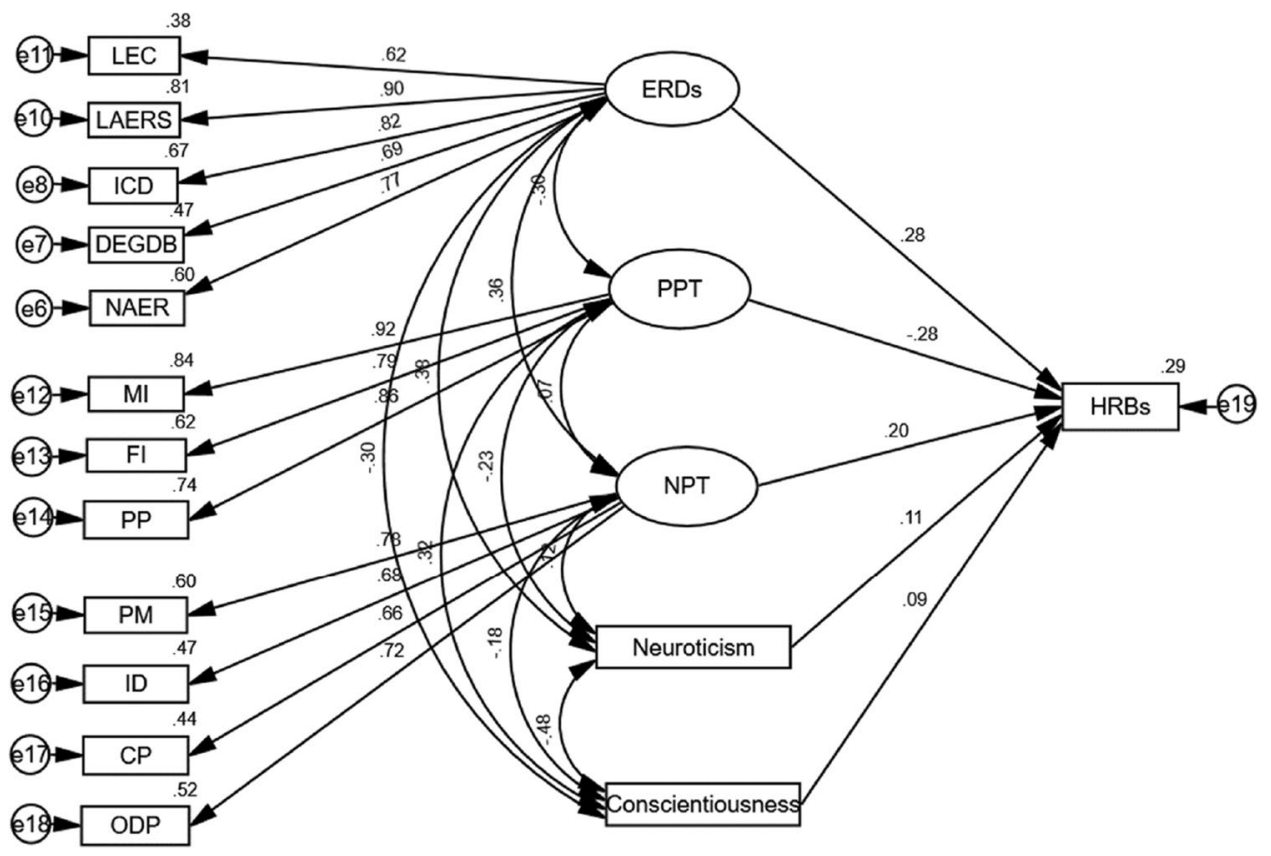

Fig. 1 Model predicting health-risk behaviours including both latent (emotion regulation difficulties, positive parenting, negative parenting) and observed exogenous variables (neuroticism and conscientiousness). Note. LEC- Lack of Emotional Clarity, LAERS-Limited Access to Emotion Regulation Strategies, ICD- Impulse Control Difficulties, DEGDB- Difficulty Engaging in Goal-Directed Behaviour, NAER- Non-Acceptance of Emotional Responses, ERDs- Emotion

Thorpe, 2010; Friedman, 2000; Newman et al., 2008; Smith, 2006; Weiss et al., 2015); however, the previous studies mainly explored these predictors individually, and mainly
Regulation Difficulties, MI- Perceived Mother Involvement, FI- Perceived Father Involvement, PP- Positive Parenting Practices, PPTPositive Parenting, PM- Poor Monitoring by Parents, ID- Inconsistent Discipline at home, CP- Corporal Punishment, ODP- Other Maladaptive Disciplinary Practices, NPT-Negative Parenting, HRBs-healthrisk behaviours

among the adult sample. The present study's findings can be explained with a common notion, described systematically as the 'problem behaviour theory' by Donovan et al. (1993). 
This theory states that healthy or unhealthy behaviours are the product of various risk and protective factors. Donovan et al. (1993) suggested an underlying 'risk behaviour syndrome', comprising of various personality, situational and behavioural factors, and manitained that a unique combination of these may predispose adolescents to acquire unhealthy, problematic behaviours (Hirani et al., 2018). In the present study, more emotion regulation difficulties, neuroticism and perceived negative parenting practices in the family are identified as significant risk factors for engagement in HRBs. Positive parenting and conscientiousness are found to be the protective factors; however, analysis reveals that high emotion regulation difficulties suppress the beneficial effect of conscientiousness on HRBs.

Emotion regulation difficulties emerged as the strongest predictor of HRBs. Emotions generally coordinate a fullbody response that allows us to quickly produce, inhibit or change our overall behavioural reaction to the stimuli in order to optimize efforts required to achieve the desired goals (Gross, 1999). However, when a person fails to regulate one's emotions appropriately, emotions become less effective and may lead to maladaptive behaviours, including HRBs (Gratz \& Roemer, 2004; Gross, 2015). Previous research on adult samples indicates that individuals who face difficulties regulating their emotions may feel distressed and indulge in HRBs (Cooper et al., 2006; Horne \& Csipke, 2009; Sher \& Grekin, 2007; Sim \& Zeman, 2005). Such indulgence is mistakenly expected to soothe negative emotions (Berking et al., 2008; Garofalo \& Velotti, 2017; Lansing et al., 2019; Weiss et al., 2015).

Various plausible mechanisms explain why emotion regulation difficulties induce maladaptive, unpleasant emotions and why failure to regulate such emotions increase the probability of engaging in HRBs. Limited clarity or awareness about ones' emotions and their dynamics, one of the emotion regulation difficulties measured in the present study, may make it difficult for individuals to understand the "emotion trajectory', how it gets triggered, and how it functions during behaviour execution. Lack of awareness and understanding generally affect how one modulate reactions to emotionally competent stimuli (Gratz \& Roemer, 2004; Mayer et al., 2003); mostly, it leads to negative emotions. Research has demonstrated that when people experience high levels of negative emotion and resulting distress, they act impulsively in an attempt to decrease this distress, prioritizing shortterm soothing activities like risky driving, poor dieting over other effective strategies (Al-Musharaf, 2020; Hayley et al., 2017; Haynos \& Fruzzetti, 2011; Tice et al., 2001; Trógolo et al., 2014).

Individuals with difficulties accessing appropriate emotion regulation strategies during their encounter with emotionally competent situations may indulge in other activities that are easily accessible regardless of their detrimental long-term effects. These findings are consistent with previous studies exploring the relationship between emotional dysregulation and violence (Garofalo et al., 2020; Shorey et al., 2015; Stappenbeck et al., 2016). Individuals with a few available emotion regulation strategies and the inability to control their emotions under high emotional arousal can indulge in proactive violence, self-harm or any other behaviour that immediately releases their negative emotions (Miles et al., 2017).

Thus, the emotion regulation difficulties may cause dysfunctional emotions, which needs to be regulated. However, either the inaccessibility of effective strategies when required or the lack of such strategies and/or executive skills may prolong the experience of dysfunctional emotions and related distress. In such conditions, individuals may use less helpful or dysfunctional coping strategies, including HRBs, to deal with their negative emotions or moods. (Gratz \& Roemer, 2004). Often, HRBs represent an attempt to cope with distress and improve or avoid negative emotions (Berking et al., 2008).

The findings regarding the role of perceived parenting practices in adolescents' HRBs can be explained within the broad 'primary socialization theory' perspective (PST; Francis \& Thorpe, 2010; Oetting \& Donnermeyer, 1998). It maintains that HRBs are learned in social contexts and are influenced by interpersonal interactions with the primary agents of socialization, such as parents and peers. The theory postulates that parental monitoring and involvement significantly impact adolescents' engagement in healthpromoting and compromising behaviours. Adolescents whose parents tend to be disengaged or uninvolved may feel rejected and experience negative emotions, dysregulation of which may move them toward HRBs. Hirschi and Gottfredson (1993) proposed that parenting practices influence self-control, and it further affects adolescents' indulgence in thrill-seeking behaviour, such as risky driving, unsafe sexual activities, violence and self-harm (Hirschi, 1969). Focusing on another perspective, the Interpersonal Acceptance-Rejection Theory (IPAR Theory; Rohner, 2016) suggested that adolescents who have a positive and accepting relationship with their parents tend to use more positive coping strategies. In contrast, adolescents who are rejected and neglected by their parents tend to engage in inappropriate behaviours as a coping mechanism to deal with the rejection (Rohner, 2016). The findings of the present study imply that the parents who practice positive parenting and involve more with children in routine activities can easily monitor maladaptive behaviours and instruct them to regulate their behaviour whenever the same is detected. On the other hand, parenting practices such as inconsistent discipline, corporal punishment and poor monitoring may not guide children about the right direction of their behaviours, either due to poor detection of maladaptive behaviours or poor efficacy 
of parenting strategies such as inconsistent discipline and corporal punishment. The present study supports the existing literature (Liu, 2019; Margolis et al., 2020; Prino et al., 2016; Sleddens et al., 2011) and suggests that parenting practices (actual/perceived; negative/positive) significantly impact adolescents' indulgence in HRBs.

The present study found neuroticism as a significant predictor of HRBs. Neuroticism has been implicated in poor health outcomes, and HRBs are believed to mediate the neuroticism-adverse health link (e.g., Weston \& Jackson, 2015). The health behaviour model of personality suggests that personality impacts health and mortality indirectly via specific behaviours (Turiano et al., 2012). Personality predisposes individuals with certain levels of specific traits to engage in some form of HRBs over their lifetimes (Murray \& Booth, 2015). Studies have also observed a direct association between personality traits and various HRBs such as smoking (Graham et al., 2017), alcohol consumption (Turiano et al., 2015), unprotected sex (Trobst et al., 2000), and physical activity (Graham et al., 2018).

Regarding the observed association, one theoretical perspective links neuroticism and health-risk behaviours with intermediate affective processes. Neuroticism significantly predicts negative affect (anxiety, depression) and perceived stress (Mroczek \& Almeida, 2004; Suls et al., 1998), and the lack of ability to regulate these negative emotions and stress predispose individuals to engage in poor health behaviours to alleviate perceived stress and negative affect (Eysenck, 1991). Though this self-medication provides short-term psychological relief, it has a physical health cost.

Gray's Behavioral Inhibition System (BIS; Gray, 1981, 1988, 1994) explains why people high in neuroticism experience greater negative affect and perceived stress and consequently indulge more in HRBs. According to this model, it is the threat sensitivity that underlies the activation of negative emotion and behavioural withdrawal. Some individuals have more sensitive BIS than others, making them more responsive to real or perceived threats - these persons are generally high in neuroticism (Gray, 1994). Therefore, these hypersensitive individuals are more likely to get into HRBs to alleviate the unpleasantness that arises from BIS activation.

John and Gross (2004), taking a similar perspective, stated that individuals low in neuroticism experience fewer and less strong negative emotions and, as a result, are not required to deal with consequences of negative affectivity. This state may make it easier for them to use adaptive and effective regulation strategies early in the process of emotion generation than it is for individuals high in neuroticism (John \& Gross, 2004). Thus, it is assumed that neuroticism makes an individual susceptible to experience more negative emotions and the inability to regulate one's negative emotions drive them to indulge in HRBs. Future studies should explore the mediational role of emotion regulation difficulties in the neuroticism-HRBs relationship.

As mentioned earlier, the finding regarding conscientiousness requires in-depth exploration. Conscientiousness correlated negatively with HRBs; however, when added to the model as a component, it emerged as a positive predictor of HRBs. Scores on conscientiousness and HRBs, and their zero-order correlation show that individuals high on conscientiousness reported less engagement in HRBs than their counterparts. Previous studies also observed a similar relationship (Bogg \& Roberts, 2004). Due to less constraint, individuals low on conscientiousness are more likely to engage in HRBs to gratify their impulses immediately. On the other hand, individuals high on conscientiousness experience more health-protective benefits, possibly because they are more careful in executing behaviours and more concerned with the accumulated effects of their behaviours (e.g., diet and exercise). In addition to disinhibition and constraint, a few other domains of conscientiousness, such as responsibility and traditionalism, may be the reasons for lessor engagement in HRBs (Donovan et al., 1991). When conscientiousness was added in the regression model with other predictors, the coefficient turned out to be positive, a case of suppression effect. Emotion regulation difficulties may be a potential mediator between conscientiousness-HRBs link. As this finding was beyond the scope of the present paper, no further exploration was done about this suppression effect, and the same will be explored independently.

The results of this study should be generalized cautiously due to some inherent limitations. The measures utilized in this study are self-report measures; thus, the possibilities of socially desirable responses cannot be ruled out. However, the self-report technique should be more helpful as individuals can better state their emotional and behavioural tendencies than external observers (Raine et al., 2006). Besides, low mean scores of some HRBs and slight deviance from normality might have affected the correlation coefficients. The cross-sectional design may also be considered a limitation; future studies may confirm the findings in longitudinal studies. Besides, the multi-level analysis, including more predictors, might have provided a better understanding of studied HRBs.

To conclude, the study highlighted the existing significance of emotion regulation difficulties, parenting practices, and personality for developing and maintaining HRBs among adolescents, and the proposed model fits well with the data. The study expands the literature about the fundamental understanding of HRBs while providing some empirical observations about the underlying dynamics among the Indian population. Significant variance in HRBs can be attributed to the emotion regulation difficulties, perceived parenting practices and personality traits. The findings suggest that researchers and practitioners should consider these 
variables while developing intervention programs targeting HRBs. In other words, the findings imply that some forms of emotion regulation interventions and positive parenting training can reduce adolescents' tendency to indulge in HRBs. The implication has some support in the existing literature, e.g., Houck et al. (2016) evaluated the usefulness of an intervention targeting one of the studied variables, i.e., emotion regulation difficulties, and observed its significant effect on adolescents' indulgence in violence and sexual risk behaviour. Such interventions should target all three factors, and their efficacy in a broader range of HRBs should be tested. Assessment and identification of emotional regulation difficulties, dysfunctional parenting practices and maladaptive personality traits during adolescence may be a better time to bring changes in these domains, as the most significant changes in these domains are said to occur in early adulthood (Roberts et al., 2006). Schools or similar institutes can sensitize students about the role of their emotion regulation styles and personality traits in promoting mental and physical health. Students can be taught a few compatible adaptive emotion regulation strategies with the ultimate goal of increasing available emotion regulation strategies, enhancing emotional awareness, clarity, healthy expression and acceptance of emotions. Similarly, parents can be sensitized about their involvement in promoting adolescents' mental and physical health.

Funding The study was funded by the Indian Council of Medical Research, New Delhi (India) through Grant no. Adhoc/136/2019/HSR.

Data Availability The data that support the findings of this study are available from the corresponding author upon reasonable request.

\section{Declarations}

Ethical Statement The research reported in the manuscript was conducted in accordance with general ethical guidelines in psychology. Ethics clearance was provided by the Institute's Ethics Committee (Human), through letter no. IEC/11/2019.

Conflict of Interest Single authored article and there is no conflict of interest to disclose.

\section{References}

Alloy, L. B., Abramson, L. Y., Smith, J. M., Gibb, B. E., \& Neeren, A. M. (2006). Role of parenting and maltreatment histories in unipolar and bipolar mood disorders: Mediation by cognitive vulnerability to depression. Clinical Child and Family Psychology Review, 9(1), 23-64. https://doi.org/10.1007/s10567-006-0002-4

Al-Musharaf, S. (2020). Prevalence and predictors of emotional eating among healthy young Saudi Women during the COVID-19 pandemic. Nutrients, 12(10), 2923. https://doi.org/10.3390/nu121 02923
Bailey, J. M., Regan, T. W., Bartlem, K. M., Wiggers, J. H., Wye, P. M., \& Bowman, J. A. (2019). A survey of the prevalence of modifiable HRBs among carers of people with a mental illness. BMC Public Health, 19(1), 1-10. https://doi.org/10.1186/ s12889-019-7577-4

Baumrind, D. (1991). The influence of parenting style on adolescent competence and substance use. The Journal of Early Adolescence, 11(1), 56-95. https://doi.org/10.1177/0272431691111004

Berking, M., Orth, U., Wupperman, P., Meier, L. L., \& Caspar, F. (2008). Prospective effects of emotion-regulation skills on emotional adjustment. Journal of Counseling Psychology, 55(4), 485-494. https://doi.org/10.1037/a0013589

Blissett, J., \& Haycraft, E. (2008). Are parenting style and controlling feeding practices related? Appetite, 50(2-3), 477-485. https:// doi.org/10.1016/j.appet.2007.10.003

Bogg, T., \& Roberts, B. W. (2004). Conscientiousness and healthrelated behaviors: A Meta-analysis of the leading behavioral contributors to mortality. Psychological Bulletin, 130(6), 887-919. https://doi.org/10.1037/0033-2909.130.6.887

Bozzini, A. B., Bauer, A., Maruyama, J., Simões, R., \& Matijasevich, A. (2020). Factors associated with risk behaviors in adolescence: A systematic review. Brazilian Journal of Psychiatry. https://doi. org/10.1590/1516-4446-2019-0835

Centre for Disease Control and Prevention (2019). Youth risk behavior survey: Data summary \& trends report 2007-2017. Retrieved from https://www.cdc.gov/healthyyouth/data/yrbs/pdf/trendsrepo rt.pdf.

Chadda, R. K., \& Deb, K. S. (2013). Indian family systems, collectivistic society and psychotherapy. Indian Journal of Psychiatry, 55(2), 299-309. https://doi.org/10.4103/0019-5545.105555

Cohen, J. (1988). Statistical power analysis for the behavioral sciences. L. Erlbaum Associates.

Cohen, J. (1992). Statistical Power Analysis. Current Directions in Psychological Science, 1(3), 98-101. https://doi.org/10.1111/ 1467-8721.ep10768783

Cooper, M. L., Flanagan, M. E., Talley, A. E., \& Micheas, L. (2006). Individual differences in emotion regulation and their relation to risk taking during adolescence. In D. K. Snyder, J. A. Simpson, \& N. J. Hughes (Eds.), Emotion regulation in couples and families: Pathways to dysfunction and health (pp. 183-203). American Psychological Association.

Costa, P. T., \& McCrae, R. R. (1992). NEO PI-R: Professional manual. Revised NEO personality inventory NEO PR-R and NEO fivefactor inventory NEO-RRI. Psychological Assessment Resources.

Dandona, R., Kumar, G. A., Dhaliwal, R. S., Naghavi, M., Vos, T., Shukla, D. K., ... \& Dandona, L. (2018). Gender differentials and state variations in suicide deaths in India: the Global Burden of Disease Study 1990-2016. The Lancet Public Health, 3(10), e478-e489. https://www.sciencedirect.com/science/article/pii/ S2468266718301385

de Graaf, H., Vanwesenbeeck, I., Woertman, L., \& Meeus, W. (2011). Parenting and Adolescents' Sexual Development in Western Societies. European Psychologist, 16(1), 21-31. https://doi.org/ 10.1027/1016-9040/a000031

Dhavan, P., Stigler, M. H., Perry, C. L., Arora, M., \& Reddy, K. S. (2009). Patterns of tobacco use and psychosocial risk factors among students in 6th through 10th grades in India: 20042006. Asian Pacific Journal of Cancer Prevention: APJCP, 10(5), 807-813. Retrieved from https://pubmed.ncbi.nlm.nih.gov/20104 $970 /$

Donovan, J. E., Jessor, R., \& Costa, F. M. (1991). Adolescent health behavior and conventionality-unconventionality: An extension of problem-behavior therapy. Health Psychology, 10(1), 52-61. https://doi.org/10.1037/0278-6133.10.1.52

Donovan, J. E., Jessor, R., \& Costa, F. M. (1993). Structure of healthenhancing behavior in adolescence: A latent-variable approach. 
Journal of Health and Social Behavior, 34, 346-362. https://doi. org/10.2307/2137372

Eysenck, H. J. (1991). Smoking, personality, and stress: Psychosocial factors in the prevention of cancer and coronary heart disease. Springer.

Fanous, A. H., Neale, M. C., Aggen, S. H., \& Kendler, K. S. (2007). A longitudinal study of personality and major depression in a population-based sample of male twins. Psychological Medicine, 37(8), 1163-1172. https://doi.org/10.1017/s0033291707000244

Florenzano, U. R., Valdés, C. M., Cáceres, C. E., Santander, R. S., Aspillaga, H. C., \& Musalem, A. C. (2011). Relación entre ideación suicida y estilos parentales en un grupo de adolescentes chilenos [Relation between suicidal ideation and parenting styles among a group of Chilean adolescents]. Revista Médica de Chile, 139(12), 1529-1533. https://doi.org/10.4067/s0034-9887201100 1200001

Francis, S. A., \& Thorpe, R. J. (2010). Using the primary socialization theory to predict substance use and sexual risk behaviors between black and white adolescents. Substance Use \& Misuse, 45(13), 2113-2129. https://doi.org/10.3109/10826081003682248

Frick, P. J. (1991). The Alabama parenting questionnaire. Unpublished rating scale, University of Alabama.

Friedman, H. S. (2000). Long-term relations of personality and health: dynamisms, mechanisms, tropisms. Journal of Personality, 68(6), 1089-1107. https://doi.org/10.1111/1467-6494.00127

Garofalo, C., \& Velotti, P. (2017). Negative emotionality and aggression in violent offenders: The moderating role of emotion dysregulation. Journal of Criminal Justice, 51, 9-16. https://doi.org/ 10.1016/j.jcrimjus.2017.05.015

Garofalo, C., Neumann, C. S., Kosson, D. S., \& Velotti, P. (2020). Psychopathy and emotion dysregulation: More than meets the eye. Psychiatry Research, 290, 113160. https://doi.org/10.1177/ 0886260519900946

Ghule, M., Donta, B. (2011). Correlates of sexual behaviour of rural college youth in Maharashtra, India. Eastern Journal of Medicine,16(2), 122-132. Retrieved from https://eastjmed.org/jvi. aspx ?un $=$ EJM-00694\& volume $=16 \&$ issue $=2$

Gibbons, J. L., \& Poelker, K. E. (2019). Adolescent development in a cross-cultural perspective. In K. D. Keith (Ed.), Cross-cultural psychology: Contemporary themes and perspectives (2nd ed., pp. 190-215). Wiley-Blackwell.

Glanz, K., Rimer, B. K., \& Viswanath, K. (2015). Health behavior: Theory, research, and practice (Jossey-Bass Public Health) (5th ed.). Jossey-Bass.

Graham, E. K., Bastarache, E. D., Milad, E., Turiano, N. A., Cotter, K. A., \& Mroczek, D. K. (2018). Physical activity mediates the association between personality and biomarkers of inflammation. SAGE Open Medicine, 6, 205031211877499. https://doi.org/10. $1177 / 2050312118774990$

Graham, E. K., Rutsohn, J. P., Turiano, N. A., Bendayan, R., Batterham, P. J., Gerstorf, D., Katz, M. J., Reynolds, C. A., Sharp, E. S., Yoneda, T. B., Bastarache, E. D., Elleman, L. G., Zelinski, E. M., Johansson, B., Kuh, D., Barnes, L. L., Bennett, D. A., Deeg, D. J., Lipton, R. B., . . Mroczek, D. K. (2017). Personality predicts mortality risk: An integrative data analysis of 15 international longitudinal studies. Journal of Research in Personality, 70, 174-186.https://doi.org/10.1016/j.jrp.2017.07.005

Graham, E. K., Weston, S. J., Turiano, N. A., Aschwanden, D., Booth, T., Harrison, F., James, B. D., Lewis, N. A., Makkar, S. R., Mueller, S., Wisniewski, K. M., Yoneda, T., Zhaoyang, R., Spiro, A., Willis, S., Schaie, K. W., Sliwinski, M., Lipton, R. A., Katz, M. J., ... Mroczek, D. K. (2020). Is Healthy Neuroticism Associated with Health Behaviors? A Coordinated Integrative Data Analysis. Collabra: Psychology, 6(1). https://doi.org/10.1525/ collabra. 266
Gratz, K. L., \& Roemer, L. (2004). Multidimensional assessment of emotion regulation and dysregulation: Development, factor structure, and initial validation of the difficulties in emotion regulation scale. Journal of Psychopathology and Behavioral Assessment, 26(1), 41-54. https://doi.org/10.1007/s10862-008-9102-4

Gray, J. A. (1981). A critique of Eysenck's theory of personality. In H. J. Eysenck (Ed.), A model for personality (pp. 246-276). Springer.

Gray, J. A. (1988). The psychology of fear and stress (problems in the behavioural sciences, series number 5) (2nd ed.). Cambridge University Press.

Gray, J. A. (1994). Personality dimensions and emotion systems. In P. Ekman \& R. J. Davidson (Eds.), The nature of emotion: Fundamental questions (pp. 329-331). Oxford University Press.

Gross, J. J. (1999). Emotion and emotion regulation. In L. A. Pervin \& O. P. John (Eds.), Handbook of personality: Theory and research (2nd ed., pp. 525-552). Guilford.

Gross, J. J. (2015). Emotion regulation: Current status and future prospects. Psychological Inquiry, 26(1), 1-26. https://doi.org/ 10.1080/1047840X.2014.940781

Gutman, L. M., \& Feinstein, L. (2010). Parenting behaviours and children's development from infancy to early childhood: Changes, continuities and contributions. Early Child Development and Care, 180(4), 535-556. https://doi.org/10.1080/0300443080 2113042

Hairs, J. F., Black, W. C., Babin, B. J., \& Anderson, R. E. (2009). Multivariate data analysis (7th ed.). Pearson.

Hallion, L. S., Steinman, S. A., Tolin, D. F., \& Diefenbach, G. J. (2018). Psychometric properties of the Difficulties in Emotion Regulation Scale (DERS) and its short forms in adults with emotional disorders. Frontiers in Psychology, 9, 539. https://doi.org/ 10.3389/fpsyg.2018.00539

Hamzah, S. R., Suandi, T., Ismail, M., \& Muda, Z. (2018). Association of the personal factors of culture, attitude and motivation with health behavior among adolescents in Malaysia. International Journal of Adolescence and Youth, 24(2), 149-159. https://doi. org/10.1080/02673843.2018.1482772

Hapunda, G., Mahama, S., Mesurado, B., Verma, S. K., \& Koller, S. (2019). Cultural variability and consistency in adolescents' emotional regulation and relationship with their parents: Data from Argentina, Ghana, India and Zambia. International Journal of Adolescence and Youth, 24(3), 333-350. https://doi.org/10.1080/ 02673843.2018 .1544083

Harakeh, Z., Scholte, R. H. J., Vermulst, A. A., de Vries, H., \& Engels, R. C. M. E. (2010). The relations between parents' smoking, general parenting, parental smoking communication, and adolescents' smoking. Journal of Research on Adolescence, 20(1), 140-165. https://doi.org/10.1111/j.1532-7795.2009.00626.x

Hardie, B. (2021). Why monitoring doesn't always matter: The interaction of personal propensity with physical and psychological parental presence in a situational explanation of adolescent offending. Deviant Behavior, 42(3), 329-352. https://doi.org/ 10.1080/01639625.2019.1673924

Hayley, A. C., de Ridder, B., Stough, C., Ford, T. C., \& Downey, L. A. (2017). Emotional intelligence and risky driving behaviour in adults. Transportation Research Part f: Traffic Psychology and Behaviour, 49, 124-131. https://doi.org/10.1016/j.trf.2017.06. 009

Haynos, A. F., \& Fruzzetti, A. E. (2011). Anorexia nervosa as a disorder of emotion dysregulation: Evidence and treatment implications. Clinical Psychology: Science and Practice, 18(3), 183202. https://doi.org/10.1111/j.1468-2850.2011.01250.x

Higgins, S. T. (2014). Behavior change, health, and health disparities: An introduction. Preventive Medicine, 68, 1-4. https://doi.org/ 10.1016/j.ypmed.2014.10.007 
Hirani, K., Cherian, S., Mutch, R., \& Payne, D. N. (2018). Identification of HRBs among adolescent refugees resettling in Western Australia. Archives of Disease in Childhood, 103(3), 240-246. https://doi.org/10.1136/archdischild-2017-31345

Hirschi, T. (1969). Causes of delinquency. University of California Press.

Hirschi, T., \& Gottfredson, M. (1993). Commentary: Testing the general theory of crime. Journal of Research in Crime and Delinquency, 30(1), 47-54. https://doi.org/10.1177/002242789303000 1004

Horne, O., \& Csipke, E. (2009). From feeling too little and too much, to feeling more and less? A nonparadoxical theory of the functions of self-harm. Qualitative Health Research, 19(5), 655-667. https://doi.org/10.1177/1049732309334249

Houck, C. D., Barker, D. H., Hadley, W., Brown, L. K., Lansing, A., Almy, B., \& Hancock, E. (2016). The 1-year impact of an emotion regulation intervention on early adolescent health risk behaviors. Health Psychology : Official Journal of the Division of Health Psychology, American Psychological Association, 35(9), 1036-1045. https://doi.org/10.1037/hea0000360

Jessor, R. (1991). Risk behavior in adolescence: A psychosocial framework for understanding and action. Journal of Adolescent Health, 12(8), 597-605. https://doi.org/10.1016/1054-139x(91)90007-k

John, O. P., \& Gross, J. J. (2004). Healthy and unhealthy emotion regulation: Personality processes, individual differences, and life span development. Journal of Personality, 72(6), 1301-1334. https:// doi.org/10.1111/j.1467-6494.2004.00298.x

Kaplan, R. M. (2014). Behavior change and reducing health disparities. Preventive Medicine, 68, 5-10. https://doi.org/10.1016/j.ypmed. 2014.04.014

Keeler, H. J., \& Kaiser, M. M. (2010). An integrative model of adolescent health risk behavior. Journal of Pediatric Nursing, 25(2), 126-137. https://doi.org/10.1016/j.pedn.2009.01.005

Kumar, S., Mahabalaraju, D., \& Anuroopa, M. (2007). Prevalence of obesity and its influencing factor among affluent school children of Davangere city. Indian Journal of Community Medicine, 32(1), 15. https://doi.org/10.4103/0970-0218.53384

Lansing, A. E., Plante, W. Y., Golshan, S., Fennema-Notestine, C., \& Thuret, S. (2019). Emotion regulation mediates the relationship between verbal learning and internalizing, trauma-related and externalizing symptoms among early-onset, persistently delinquent adolescents. Learning and Individual Differences, 70, 201-215. https://doi.org/10.1016/j.lindif.2017.01.014

Lima, C. A. G., Maia, M. D. F. M., Brito, M. F. S. F., Pinho, L. D., \& Silveira, M. F. (2020). Psychometric Properties of the Youth Risk Behavior Survey (YRBS) Instrument in Brazilian College Students. Paidéia (Ribeirão Preto), 30.https://doi.org/10.1590/ 1982-4327e3006

Liu, X. (2019). Parenting styles and health risk behavior of left-behind children: The mediating effect of cognitive emotion regulation. Journal of Child and Family Studies, 29(3), 676-685. https://doi. org/10.1007/s10826-019-01614-2

Malouff, J. M., Thorsteinsson, E. B., \& Schutte, N. S. (2005). The relationship between the five-factor model of personality and symptoms of clinical disorders: A meta-analysis. Journal of Psychopathology and Behavioral Assessment, 27(2), 101-114. https://doi.org/10.1007/s10862-005-5384-y

Margolis, A., Rice, T., Banikya-Leaseburg, M., Person, A. E., Clary, E., Zief, S., ... \& Harding, J. F. (2020). Meeting the multifaceted needs of expectant and parenting young families through the Pregnancy Assistance Fund. Maternal and Child Health Journal, 24, 76-83. https://doi.org/10.1007/s10995-020-02922-6

Mayer, J. D., Salovey, P., Caruso, D. R., \& Sitarenios, G. (2003). Measuring emotional intelligence with the MSCEIT V2.
0. Emotion, 3(1), 97. https://psycnet.apa.org/doi/https://doi.org/ 10.1037/1528-3542.3.1.97.

Miles, S. R., Sharp, C., Tharp, A. T., Stanford, M. S., Stanley, M., Thompson, K. E., \& Kent, T. A. (2017). Emotion dysregulation as an underlying mechanism of impulsive aggression: Reviewing empirical data to inform treatments for veterans who perpetrate violence. Aggression and Violent Behavior, 34, 147-153. https:// doi.org/10.1016/j.avb.2017.01.017

Mroczek, D. K., \& Almeida, D. M. (2004). The effect of daily stress, personality, and age on daily negative affect. Journal of Personality, 72(2), 355-378. https://doi.org/10.1111/j.0022-3506. 2004.00265.x

Murray, A. L., \& Booth, T. (2015). Personality and physical health. Current Opinion in Psychology, 5, 50-55. https://doi.org/10. 1016/j.copsyc.2015.03.011

Napier, A. D., Ancarno, C., Butler, B., Calabrese, J., Chater, A., Chatterjee, H., Guesnet, F., Horne, R., Jacyna, S., Jadhav, S., Macdonald, A., Neuendorf, U., Parkhurst, A., Reynolds, R., Scambler, G., Shamdasani, S., Smith, S. Z., Stougaard-Nielsen, J., Thomson, L., ... Woolf, K. (2014). Culture and health. The Lancet, 384(9954), 1607-1639.https://doi.org/10.1016/s0140-6736(14) 61603-2

Narain, R., Sardana, S., Gupta, S., \& Sehgal, A. (2011). Age at initiation \& prevalence of tobacco use among school children in Noida, India: a cross-sectional questionnaire-based survey. The Indian Journal of Medical Research, 133(3), 300-307. Retrieved from https://www.ncbi.nlm.nih.gov/pmc/articles/PMC3103155/

Newman, K., Harrison, L., Dashiff, C., \& Davies, S. (2008). Relationships between parenting styles and risk behaviors in adolescent health: An integrative literature review. Revista Latino-Americana De Enfermagem, 16(1), 142-150. https://doi.org/10.1590/ S0104-11692008000100022

Nielsen, M., Haun, D., Kärtner, J., \& Legare, C. H. (2017). The persistent sampling bias in developmental psychology: A call to action. Journal of Experimental Child Psychology, 162, 31-38. https:// doi.org/10.1016/j.jecp.2017.04.017

Oetting, E. R., \& Donnermeyer, J. F. (1998). Primary socialization theory: The etiology of drug use and deviance. I. Substance Use \& Misuse, 33(4), 995-1026. https://doi.org/10.3109/1082608980 9056252

Pengpid, S., \& Peltzer, K. (2020). High psychological distress among school-going adolescents in Afghanistan: Prevalence and correlates from a national survey. Vulnerable Children and Youth Studies, 15(1), 40-47. https://doi.org/10.1080/17450128.2019. 1679937

Prino, L. E., Rollè, L., Sechi, C., Patteri, L., Ambrosoli, A., Caldarera, A. M., ... \& Brustia, P. (2016). Parental relationship with twins from pregnancy to 3 months: the relation among parenting stress, infant temperament, and well-being. Frontiers in Psychology, 7, 1628.https://doi.org/10.3389/fpsyg.2016.01628

Raine, A., Dodge, K., Loeber, R., Gatzke-Kopp, L., Lynam, D., Reynolds, C., ... \& Liu, J. (2006). The reactive-proactive aggression questionnaire: Differential correlates of reactive and proactive aggression in adolescent boys. Aggressive Behavior: Official Journal of the International Society for Research on Aggression, 32(2), 159-171.

Ram, D., George, M., \& Gowdappa, B. (2018). Correlation of cognitive functions with emotional dysregulation in alcohol dependence: A preliminary study. Indian Journal of Psychiatry, 60(3), 307-311. https://doi.org/10.4103/psychiatry.IndianJPsychiatry_183_18

Roberts, B. W., Walton, K. E., \& Viechtbauer, W. (2006). Patterns of mean-level change in personality traits across the life course: A meta-analysis of longitudinal studies. Psychological Bulletin, 132(1), 1-25. https://doi.org/10.1037/0033-2909.132.1.1 
Rohner, R. P. (2016). Introduction to interpersonal acceptance-rejection theory (IPAR Theory) and evidence. Online Readings in Psychology and Culture, 6(1), 4. https://doi.org/10.9707/2307-0919. 1055

Ryan, S. M., Jorm, A. F., \& Lubman, D. I. (2010). Parenting factors associated with reduced adolescent alcohol use: A systematic review of longitudinal studies. Australian \& New Zealand Journal of Psychiatry, 44(9), 774-783. https://doi.org/10.1080/00048 674.2010.501759

Sher, K. J., \& Grekin, E. R. (2007). Alcohol and affect regulation. In J. J. Gross (Ed.), Handbook of emotion regulation (pp. 560-580). Guilford Press.

Sherry, S. B., Hewitt, P. L., Flett, G. L., Lee-Baggley, D. L., \& Hall, P. A. (2007). Trait perfectionism and perfectionistic self-presentation in personality pathology. Personality and Individual Differences, 42(3), 477-490. https://doi.org/10.1016/j.paid.2006. 07.026

Shorey, R. C., McNulty, J. K., Moore, T. M., \& Stuart, G. L. (2015). Emotion regulation moderates the association between proximal negative affect and intimate partner violence perpetration. Prevention Science, 16(6), 873-880. https://doi.org/10.1007/ s11121-015-0568-5

Sim, L., \& Zeman, J. (2005). Emotion regulation factors as mediators between body dissatisfaction and bulimic symptoms in early adolescent girls. The Journal of Early Adolescence, 25(4), 478-496. https://doi.org/10.1177/0272431605279838

Sleddens, E. F. C., Gerards, S. M. P. L., Thijs, C., de Vries, N. K., \& Kremers, S. P. J. (2011). General parenting, childhood overweight and obesity-inducing behaviors: A review. International Journal of Pediatric Obesity, 6(2-2), e12-e27. https://doi.org/ 10.3109/17477166.2011.566339

Smith, A. R., Chein, J., \& Steinberg, L. (2014). Peers increase adolescent risk taking even when the probabilities of negative outcomes are known. Developmental Psychology, 50(5), 1564-1568. https://doi.org/10.1037/a0035696

Smith, T. W. (2006). Personality as risk and resilience in physical health. Current Directions in Psychological Science, 15(5), 227-231. https://doi.org/10.1111/j.1467-8721.2006.00441.x

Smith, T. W., \& MacKenzie, J. (2006). Personality and risk of physical illness. Annual Review of Clinical Psychology, 2(1), 435-467. https://doi.org/10.1146/annurev.clinpsy.2.022305.095257

Sondhi, R. (2017). Parenting adolescents in India: a cultural perspective. Child and Adolescent Mental Health, 91-108.

Stappenbeck, C. A., Davis, K. C., Cherf, N., Gulati, N. K., \& Kajumulo, K. F. (2016). Emotion regulation difficulties moderate the association between heavy episodic drinking and dating violence perpetration among college men. Journal of Aggression, Maltreatment \& Trauma, 25(9), 921-935. https://doi.org/10.1080/ 10926771.2016 .1232328

Steptoe, A. (2007). Health behaviour and stress. In G. Fink (Ed.), Encyclopedia of Stress (2nd ed., pp. 263-266). Academic Press.

Suls, J., Green, P., \& Hillis, S. (1998). Emotional reactivity to everyday problems, affective inertia, and neuroticism. Personality and Social Psychology Bulletin, 24(2), 127-136. https://doi.org/10. $1177 / 0146167298242002$

Sunitha, S., \& Gururaj, G. (2014). Health behaviours \& problems among young people in India: Cause for concern \& call for action. The Indian Journal of Medical Research, 140(2), 185-208.

Tice, D. M., Bratslavsky, E., \& Baumeister, R. F. (2001). Emotional distress regulation takes precedence over impulse control: If you feel bad, do it! Journal of Personality and Social Psychology, 80(1), 53-67. https://doi.org/10.1037/0022-3514.80.1.53
Trobst, K. K., Wiggins, J. S., Costa, P. T., Jr., Herbst, J. H., McCrae, R. R., \& Masters, H. L., III. (2000). Personality psychology and problem behaviors: HIV risk and the five-factor model. Journal of Personality, 68(6), 1233-1252. https://doi.org/10.1111/14676494.00133

Trógolo, M. A., Melchior, F., \& Medrano, L. A. (2014). The role of difficulties in emotion regulation on driving behavior. Journal of Behavior, Health \& Social Issues, 6(1), 107-117. https://doi.org/ 10.5460/jbhsi.v6.1.47607

Turiano, N. A., Chapman, B. P., Gruenewald, T. L., \& Mroczek, D. K. (2015). Personality and the leading behavioral contributors of mortality. Health Psychology, 34(1), 51-60. https://doi.org/ $10.1037 /$ hea0000038

Turiano, N. A., Whiteman, S. D., Hampson, S. E., Roberts, B. W., \& Mroczek, D. K. (2012). Personality and substance use in midlife: Conscientiousness as a moderator and the effects of trait change. Journal of Research in Personality, 46(3), 295-305. https://doi. org/10.1016/j.jrp.2012.02.009

Underwood, J. M., Brener, N., Thornton, J., Harris, W. A., Bryan, L. N., Shanklin, S. L., Deputy, N., Roberts, A. M., Queen, B., Chyen, D., Whittle, L., Lim, C., Yamakawa, Y., Leon-Nguyen, M., Kilmer, G., Smith-Grant, J., Demissie, Z., Jones, S. E., Clayton, H., \& Dittus, P. (2020). Overview and methods for the youth risk behavior surveillance system - United States, 2019. MMWR supplements, 69(1), 1-10. https://doi.org/10.15585/mmwr.su690 $1 \mathrm{a} 1$.

UNICEF (2011, February). The State of the World's Children 2011: Adolescence, an Age of Opportunity (No. 978-92-806-4555-2). United Nations Children's Fund (UNICEF). Retrieved from https://data.unicef.org/resources/the-state-of-the-worlds-child ren-2011-adolescents-an-age-of-opportunity(accessed on September 24, 2021).

van den Bos, W., \& Hertwig, R. (2017). Adolescents display distinctive tolerance to ambiguity and to uncertainty during risky decision making. Scientific Reports, 7(1). https://doi.org/10.1038/srep4 0962

Vollrath, M., \& Torgersen, S. (2002). Who takes health risks? A probe into eight personality types. Personality and Individual Differences, 32(7), 1185-1197. https://doi.org/10.1016/s01918869(01)00080-0

Wang, H. (2014). The relationship between parenting styles and academic and behavioral adjustment among urban Chinese adolescents. Chinese Sociological Review, 46(4), 19-40. https://doi. org/10.2753/CSA2162-0555460402

Weiss, H. A., \& Ferrand, R. A. (2019). Improving adolescent health: An evidence-based call to action. The Lancet, 393(10176), 10731075. https://doi.org/10.1016/S0140-6736(18)32996-9

Weiss, N. H., Sullivan, T. P., \& Tull, M. T. (2015). Explicating the role of emotion dysregulation in risky behaviors: A review and synthesis of the literature with directions for future research and clinical practice. Current Opinion in Psychology, 3, 22-29. https://doi.org/10.1016/j.copsyc.2015.01.013

Weston, S. J., \& Jackson, J. J. (2015). identification of the healthy neurotic: Personality traits predict smoking after disease onset. Journal of Research in Personality, 54, 61-69. https://doi.org/ 10.1016/j.jrp.2014.04.008

Weston, S. J., Graham, E. K., Turiano, N. A., Aschwanden, D., Booth, T., Harrison, F., James, B. D., Lewis, N. A., Makkar, S. R., Mueller, S., Wisniewski, K. M., Yoneda, T., Zhaoyang, R., Spiro, A., Drewelies, J., Wagner, G. G., Steinhagen-Thiessen, E., Demuth, I., Willis, S., ... Mroczek, D. K. (2020). Is healthy neuroticism associated with chronic conditions? A coordinated integrative data analysis. Collabra: Psychology, 6(1). https://doi.org/10. 1525/collabra.267 
Weston, S. J., Hill, P. L., Edmonds, G. W., Mroczek, D. K., \& Hampson, S. E. (2018). No Evidence of "healthy neuroticism" in the Hawaii Personality and Health Cohort. Annals of Behavioral Medicine, 53(5), 426-441. https://doi.org/10.1093/abm/kay055

World Health Organization (2021, January 18). Adolescent and young adult health. Retrieved from https://www.who.int/en/news-room/ fact-sheets/detail/adolescents-health-risks-and-solutions

Zafar, H., Debowska, A., \& Boduszek, D. (2021). Emotion regulation difficulties and psychopathology among Pakistani adolescents. Clinical Child Psychology and Psychiatry, 26(1), 121-139. https://doi.org/10.1177/1359104520969765
Zlomke, K. R., Lamport, D., Bauman, S., Garland, B., \& Talbot, B. (2014). Parenting adolescents: Examining the factor structure of the Alabama Parenting Questionnaire for adolescents. Journal of Child and Family Studies, 23(8), 1484-1490. https://doi.org/ 10.1007/s10826-013-9803-5

Publisher's Note Springer Nature remains neutral with regard to jurisdictional claims in published maps and institutional affiliations. 